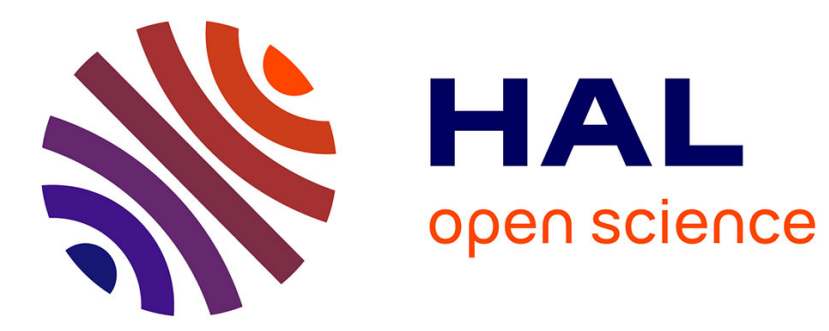

\title{
X-ray absorption near edge spectroscopy (XANES) study of thermostable polyphenylquinoxaline (PPQ) polymer prior to $\mathrm{Cu}$ thin films deposition
}

\author{
G. Richard, A. Cros, Y. Mathey, G. Tourillon, C. Laffon, Y. Parent
}

\section{- To cite this version:}

G. Richard, A. Cros, Y. Mathey, G. Tourillon, C. Laffon, et al.. X-ray absorption near edge spectroscopy (XANES) study of thermostable polyphenylquinoxaline (PPQ) polymer prior to $\mathrm{Cu}$ thin films deposition. Journal de Physique IV Proceedings, 1993, 03 (C7), pp.C7-789-C7-792. 10.1051/jp4:19937124 . jpa-00251743

HAL Id: jpa-00251743

https://hal.science/jpa-00251743

Submitted on 1 Jan 1993

HAL is a multi-disciplinary open access archive for the deposit and dissemination of scientific research documents, whether they are published or not. The documents may come from teaching and research institutions in France or abroad, or from public or private research centers.
L'archive ouverte pluridisciplinaire HAL, est destinée au dépôt et à la diffusion de documents scientifiques de niveau recherche, publiés ou non, émanant des établissements d'enseignement et de recherche français ou étrangers, des laboratoires publics ou privés. 


\title{
X-ray absorption near edge spectroscopy (XANES) study of thermostable polyphenylquinoxaline (PPQ) polymer prior to $\mathrm{Cu}$ thin films deposition
}

\author{
G. RICHARD, A. CROS, Y. MATHEY, G. TOURILLON* C. LAFFON* and Y. PARENT*
}

URA 783 du CNRS, Faculté des Sciences de Luminy, Département de Physique, Case 901, 13288 Marseille cedex 9, France

* LURE, Bât. 209D, 91405 Orsay, France

\begin{abstract}
We have studied the properties of untreated and $\mathrm{O}_{2}$ (or $\mathrm{N}_{2}$ ) plasma treated polyphenylquinoxaline (PPQ) polymer surfaces by X-ray absorption near edge spectroscopy (XANES). Upon comparing, with our previous XPS results, the measurements performed at the $\mathrm{C}$ and $\mathrm{N}-\mathrm{K}$ edges under normal or glancing incidences, it is clear that XANES provides new information on the electronic properties and on the preferential orientation of the spin coated polymer film. It is shown, in particular, that the plasma treatment strongly modifies the antibonding $\pi^{*}$ ring and $\pi^{*}{ }_{\mathrm{C}-\mathrm{H}}$ resonances.
\end{abstract}

In the general framework of our metal-polymer interface studies, we are currently investigating the $\mathrm{Cu}$ polyphenylquinoxaline polymer (PPQ) interfacial properties as a function of the polymer surface treatments. PPQ displays, figure 1 , a high thermal stability (up to $550^{\circ} \mathrm{C}$ ) and very attractive dielectric properties $\left(\varepsilon=2.8 ; \operatorname{tg} \delta<10^{-3}\right)$ [1]. This polymer appears therefore as an excellent candidate for use as dielectric layers in high density interconnects [2]; although various degradation phenomena at its interface with metal layers during aging were not perfectly understood yet [3].<smiles>IC1=NC2=CC(C3CCC4=NC(c5ccccc5)=NC(C5CCC(I)CC5)C4N3)CCC2N=C1c1ccccc1</smiles>

Fig. 1 - Chemical structure of polyphenylquinoxaline.

XPS investigation has already given significant indications concerning the role of oxygen in the surface or interface degradation process but, it has not been possible, by this technique, to distinguish between the carbon atoms in the phenyl and in the quinoxaline groups.

We report hereafter our preliminary X-ray absorption near edge spectroscopy experiments carried out at LURE, the French Synchrotron Radiation facility. Besides its ability to probe the unoccupied states of this polyaromatic rings structure through the measurements of the intensity and energy position of the resonance peaks, XANES can also provide, upon using the linear polarization of the incident X-ray beam, useful information about the orientation of the polymer film with respect to the substrate plane [4]. 


\section{AS DEPOSITED PPQ INVESTIGATION}

Three kinds of six membered aromatic rings are present in the polymer under study : two of them are fused (one is a pyrazine-like $\mathrm{C}_{4} \mathrm{~N}_{2}$ heterocyclic ring, while the other is a $\mathrm{C}_{6}$ phenyl-like ring) and they build together the so-called quinoxaline group; the third ring is a regular phenyl group.

On the basis of LCAO calculations [5] and XANES studies [6] performed on benzene and pyridine, the transitions at the carbon and nitrogen-K edges of PPQ can be expected to be grouped into two subsets : first, on the lower part of the energy scale, the $\pi^{*}$ resonances which are polarized perpendicular to the ring planes and second, the $\sigma^{*}$ resonances, occurring at higher energies (above the ionization threshold), which are polarized parallel to the ring planes of the polymer unit.

Five main peaks, labelled A-E, are observed on the carbon-K edge spectra of as-deposited polymer (figure 2) and, indeed, two subsets can be readily distinguished.

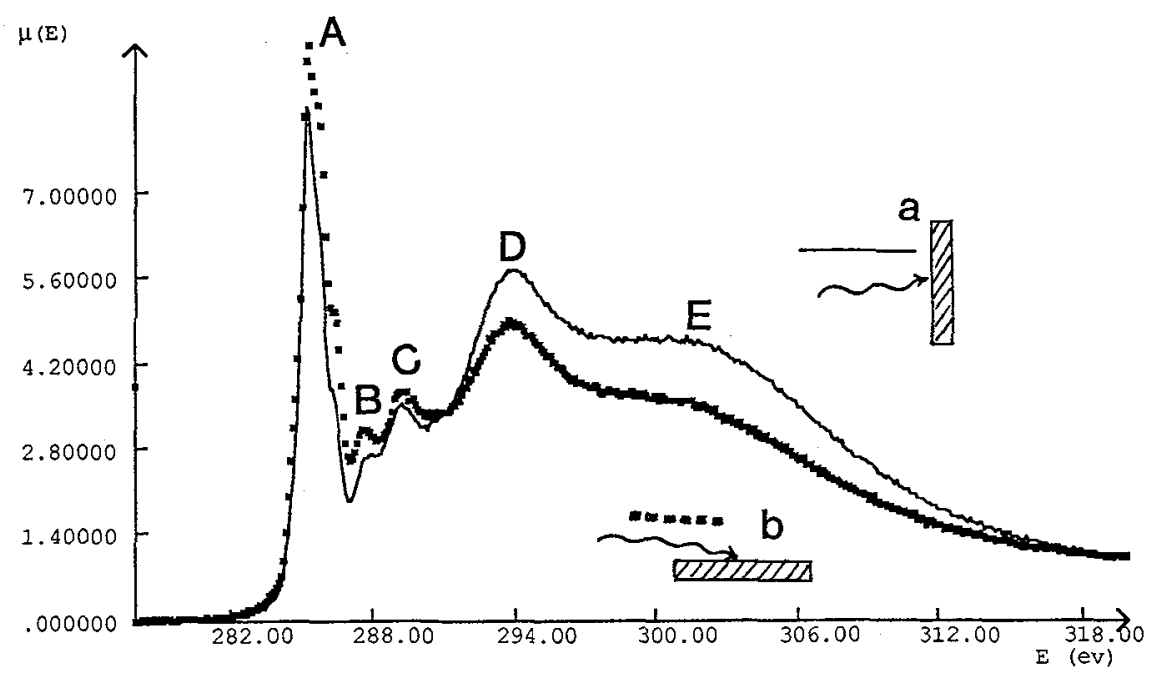

Fig. 2 - C-K edge spectra of as-deposited PPQ with either normal (trace a) or grazing (trace b) incident Xrays relative to the surface.

Peak $A$ is assigned to a $\pi$ resonance, i.e. to transitions of carbon 1 s core electrons into the lowest unoccupied $\pi^{*}$ band of the PPQ $\pi_{\text {ring }}$-system. Weak shoulders detected on the high energy side of this peak are probably related to small energy differences between carbon atoms belonging to the three different kinds of rings involved in PPQ structure. Peak C lies $3.8 \mathrm{eV}$ higher in energy than peak A; it can therefore be unambiguously assigned to carbon 1 s to the second unoccupied $\pi^{*}$ ring band transitions, as this energy separation corresponds almost exactly to those measured in XANES and EELS experiments for benzene and pyridine [6].

Peak B displays an intensity behaviour very similar to those of peaks $\mathrm{A}$ and $\mathrm{C}$ upon changing X-rays incidence. Such a $\pi$-like character on the one hand, its intermediate energy position between the two 1s$\pi^{*}$ ring bands transitions on the other, make us confident in an assignment to a $1 \mathrm{~s}-\pi^{*} \mathrm{C}-\mathrm{H}$ transition. Finally, peaks D and $\mathrm{E}$ are assigned as $\sigma$ resonances, in agreement with both the literature [4] and their 
weak polarization dependence, as depicted on figure 2 .

This last polarization effect (change in the peak A/peak D intensity ratio from 1.94 for glancing to 1.43 for normal incidence) indicates that the rings of the polymer units are not oriented at random and that a significant percentage of these units have their mean orientation parallel to the substrate plane. Such a trend is still more obvious upon considering the intensity changes observed at $\mathrm{N}-\mathrm{K}$ edge, figure 3.

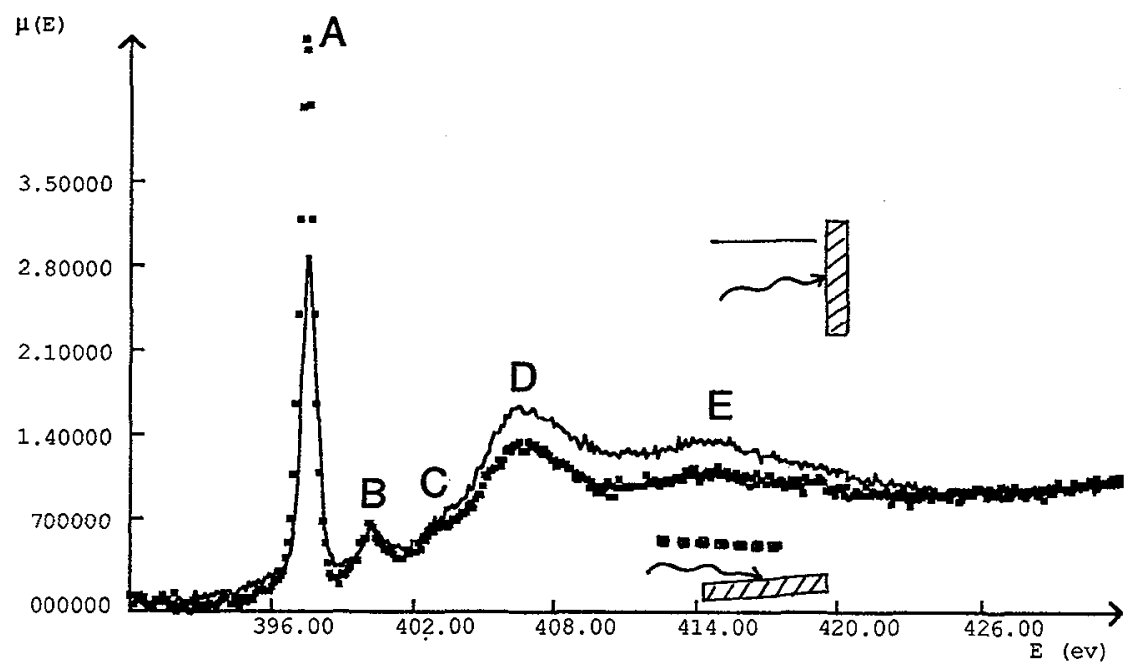

Fig. 3 - N-K edge spectra of as-deposited PPq.

The overall aspect of these spectra is relatively similar to those already described at $\mathrm{C}-\mathrm{K}$ edge and, on the same crude basis, the A-E peaks are assigned to the same transitions than before. Noticeable polarization effect (change in the peak $A /$ peak $D$ intensity ratio from 3.5 for glancing, to 1.72 for normal incidence) indicates, here also, that the mean polymer units planes are lying parallel to the substrate surface.

\section{$\mathrm{O}_{2}$ Plasma-TReated PPQ}

$\mathrm{O}_{2}$ plasma-treatment induces an important increase of the oxygen atomic concentration from none to 11.6 at \%. We have already noted by XPS the appearance of oxidized carbon atoms (involved in carbonyl or other oxigenated groups) and oxidized nitrogen atoms [3]. At first glance, XANES spectra show, figure 4 , strong modifications of all the antibonding $\pi^{*}$-related resonances.

A more detailed inspection reveals :

(i) a drastic weakening of the $\pi^{*} \mathrm{C}$-H resonance, peak B, above the $\mathrm{C}-\mathrm{K}$ edge, which may indicate the existence of a ring-opening mechanism leading to carbonyl formation and to a consecutive partial loss of aromatic character,

(ii) a new resonance (see the arrow on the spectrum), detected as a shoulder on the low energy side of peak $\mathrm{C}$, which can be assigned to a $\pi^{*}$ resonance for the newly formed carbonyl carbon atom core electrons.

(iii) an important loss of the polarization effects observed on as-deposited polymers.

In addition, a total loss of the polarization effects and a significant shift $(\sim 0.8 \mathrm{eV})$ towards higher energy values of the complete resonance spectrum are observed above the $\mathrm{N}-\mathrm{K}$ edge (spectrum not shown here). This last change corresponds probably to the formation of $\mathrm{N}$-oxide bonds in the heterocyclic subunits of the polymer. 


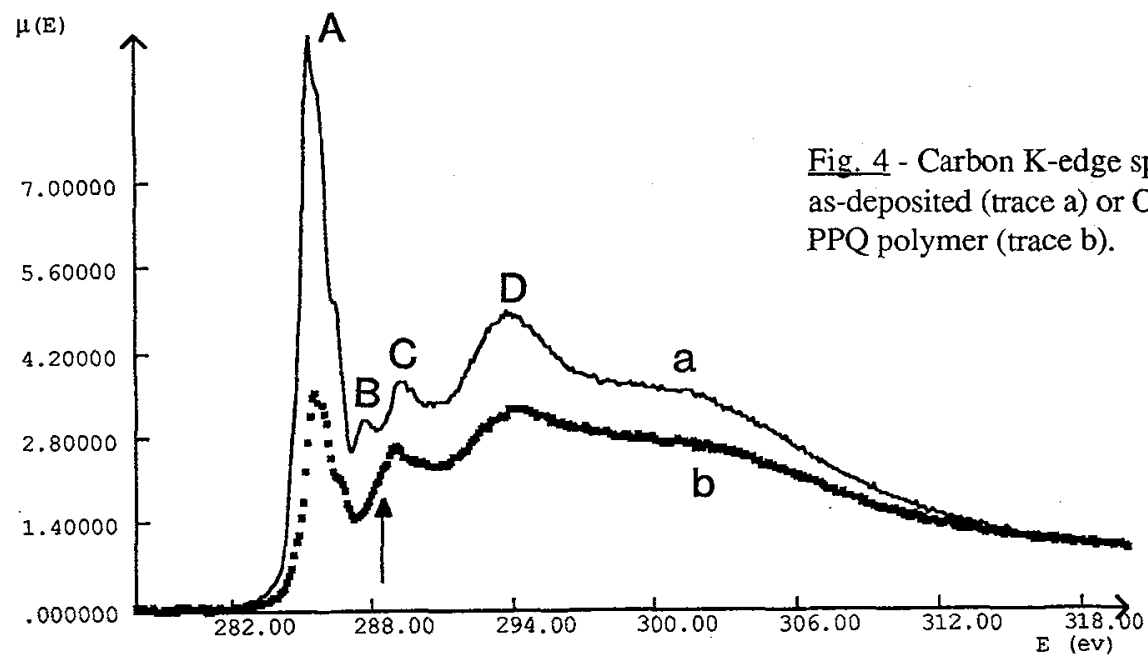

These preliminary results obtained prior to copper (or other metal) deposition are expected, upon comparison with XANES data obtained during the first stages of the metal growth, to allow a better understanding of the role of each particular subunits or rings in the interfacial metal-polymer adhesion.

\section{REFERENCES}

[1] SILLION B. and VERDET L., in "Polyimides and other high temperature polymers" ed. by J.M.Abadie and B. Sillion, Elsevier 1991, p. 363.

[2] BUREAU J.M., GRACIET M. and BERNARD F., in "Polyimides and other high temperature polymers" ed. by J.M.Abadie and B. Sillion, Elsevier 1991, p. 387.

[3] CROS A., DALLAPORTA H., LAZARE S., TEMPLIER F., NECHSTEIN J., PALLEAU J., HIRAOKA H. and TORRES J., Proceeding of the International Conference on Metallized Plastics, Phœnix, USA, 1991.

[4] HAASE J. and BRADSHAW A.M., in "Adv. Surface and Interface Science" vol. 2, ed. by R.Z. Bachrach, Plenum Press 1992, p. 55.

[5] JORGENSEN W.L. and SALEM L., in "The Organic Chemist's Book of Orbitals", Academic Press, 1973.

[6] a. JOHNSON J.A., MUETTERTIES E.L. and STÖHR J., J. Am. Chem. Soc. 105 (1983) 7183.

b. LIU A.C., STÖHR J., FRIEND C.M. and MADIX R.J., Surf. Science 235 (1990) 107.

c. BADER M., HAASE J., FRANCK K.H., PUSCHMANN A. and OTTO A., Phys. Rev. Lett. 56 (1986) 1921. 